\title{
Communicating Across Borders: A Proposed Model for Understanding Cross-Cultural Issues for the Successful Strategic Implementation of Information Systems
}

\author{
John E. Merchant \\ California State University, Sacramento, CA, USA
}

merchant@estus.edu

Abstract

While there has been a great deal of research on the application and implementation of IS, there is less research on the variables which can contribute to the successful strategic implementation of IS and its relation to the cultural/work values of the people involved in the implementation. We are familiar with the two paradigms for evaluating IS, the first calls for the evaluation to be based on the relation to design specification - or user needs. The second concentrates on the performance related aspects which consider outcome of the system. This paper presents a model, based on research of different cultures, that outlines an approach to consider in relating the correlation of IS to the Culture and Work values of the individuals in a particular cultural setting.

\section{Introduction}

In recent years, many companies, large and small, have been experiencing "the perils of going global". The expanding interdependent global economy and the accompanying changes in the structure of competition are forcing many companies to seek new ways to manage their businesses. There is a growing need of the coordination in the areas of product design, production, and distribution across country units to achieve global economies of scale and provide consistent quality service to global corporate customers. This growth of multinational business has been accompanied by significant increases in international Information Systems (IS) operations. In order to support their world wide activities and provide integrated service to worldwide customers, many companies are developing systems which can be utilized in many different areas in the world. Yet, the development of IS in a global environment is complex and significantly different from IS development within a domestic environment. Due to the differences existing in the political/legal, social/cultural, technological, and economic dimensions of the host country, as well as affiliate countries environments, the implementation of global IS appears to pose major problems.

The purpose of this paper, therefore, is to discuss one area for research of IS relationships with national culture and implementation. Specifically, it is argued that knowledge of the cultural orientation of organizational employees will greatly facilitate IS implementation, which in turn will contribute to a successful company. That is, the success of a corporation's success is significantly affected by the culture operating in an organization. Hunger and Wheelen (1995) point out that an optimal culture is one that best supports

Material published as part of these proceedings, either on-line or in print, is copyrighted by Informing Science. Permission to make digital or paper copy of part or all of these works for personal or classroom use is granted without fee provided that the copies are not made or distributed for profit or commercial advantage AND that copies 1) bear this notice in full and 2) give the full citation on the first page. It is permissible to abstract these works so long as credit is given. To copy in all other cases or to republish or to post on a server or to redistribute to lists requires specific permission from the publisher at publister@intormingscience.org the mission and strategy of the company of which it is a part. Given the fact that 25 percent to 50 percent of an employee's behavior on the job is culturally determined (Gannon, 1994), one needs to understand the cultural values behind this employee. For management, the critical challenge is to help their employees become more competitive on the job and to relate better to the global problems and 
opportunities of the company (Garland \& Farmer, 1986). Therefore, companies need to develop not just a generally favorable culture but also specific cultural characteristics to maximize the performance of their employees (Yip, 1995). They can do this in two ways. One is to understand the cultural orientation of the employees in their companies; the other is that they must understand and adjust to the work environment desired by these individuals, when implementation new technology.

One problem that we face is that there is no agreement on what elements need to be explored that facilitate the implementation of IT. Some arguments presented are that: (1) the internal condition that support strategy utilization include leadership, integration of IT, the strategic function and direct contact between IT and line divisions (Johnston and Carrico, 1988); (2) one needs to look at individual action and behavior in an organizational context (Swanson, 1987); and (3) technology, interdepartmental relations and the environment are the key factors in the transformational process (Daft and Lengel, 1986). This lack of agreement is understandable because the level of complexity inherent in any organization is a characteristic of the system's physical and social structure, and it is impacted by the total number of its individual sub-units, the number of different layers in the structural hierarchy, the number of different business processes that perform business activities, and the number and strengths of connections among all these subunits, and between these sub-units and outside economic agents. A consequence of this lack of agreement is that researchers are left to suggest and develop their own approach to studying the influence of IT on an organization.

Delone and McLean (1991) noted “... no single measure is intrinsically better than another; so choices of a success variable is often a function of the objective of the study, the organizational context, the aspects of the IS which is addressed by the study, the independent variables under investigation, the research method, and the level of analysis (i.e., individual, organization, or society

For the purposes of this research, it is argued that when managers attempt to implement IT in an organization staffed by foreign nationals, failure will occur unless the manager is able to bridge the gap between his culture and theirs. If one can make this transition, then the benefits for an organization that matches cultures are that it will become an optimal culture which:

a) conveys a sense of identify for employees;

b) helps generate employees' commitment to something greater than themselves;

c) adds to the stability of the organization as a social system; and

d) serves as a frame of reference for employees to use to make sense out of organizational activities and to use as a guide for appropriate behavior (Hunger and Wheelen, 1996).

Therefore, it follows that, "An organization can use culture or ideology as the basis of its strategic formulation" (Mintzberg, et. al., 1995). A better understanding of this process in relation to the different cultures under review is to place it in the context of the definition of culture and the various frameworks advanced to study different cultures.

\section{Culture}

As early as 1952, researchers identified more than 160 definitions of culture, and today, it is estimated that culture has been defined in approximately 400 ways (Ferraro, 1994). To undertake a large inventory would therefore be unrealistic. The purpose here is merely to supply the reader with a brief introduction to the notion. There is a common view in research concerning the basic meaning of culture: individually, we are all different, but share similar experiences with those who grew up in the same surroundings, in the same type of society as us. In this way, there are cultural differences between, for example: nations, regions, social classes, generations, men and women, religious, ethnic, and linguistic groups, minorities, and professions and organizations (those who work in a certain company and who share a corporate culture). 
Therefore, culture becomes visible in a variety of ways. Symbols, heroes, rituals and values can summarize the main elements of manifestations. One can also simply make the distinction between practices (containing the three first elements, e.g., symbols, heroes, and rituals), and values. Practices are relatively superficial elements of a culture, expressed in collective habits, such as the way in which people greet each other, their eating habits, the way in which meetings are conducted, status symbols, language and special professional vocabulary, clothing style, communication style, and especially how one behaves in an organizational setting.

Values on the on the other hand, are not visible in the same way as practices are. They form the deepest and most "hidden" dimension of culture, and are often unconscious to people. Values are one of the first things a child learns from its parents. At that time, we were taught, among others things, about what is: Good versus Evil, Clean versus Dirty, Beautiful versus Ugly, Natural versus Unnatural, Normal versus Abnormal, Logical versus Illogical, Rational versus Irrational, and Fair versus Unfair. These values are broad tendencies to prefer some conditions to others. The important point is that they were taught in the context of the environment in which one was raised and educated. That is, fair versus unfair in one society may not be the same as in another society.

An operational definition of Culture, therefore, is:

1. Something that is shared by all, or almost all members of some social group.

2. Something that the older members of the group try to pass on to the younger members.

3. Something (as in the case of morals, laws and customs) that shapes behavior, or that structures one's perception of the world. Consequently, this is why:

a) culture is always a collective phenomenon (to be distinguished from the individual level),

b) deep cultural values change relatively slowly over time,

c) collective cultural values influence the definition of laws, management styles, political institutions, the construction of theories and ways of carrying out research (Francesco and Gold, 1998).

The key terms are the values and expectations that individuals bring into the work place.

Therefore, increased knowledge about such factors as what motivates people from other cultures in how they will react under certain circumstances, in which way they make decisions and want decisions to be made, the way they communicate, how they want contracts to be stipulated, how their performance is evaluated, etc., can contribute to a reduction of the already high levels of uncertainty linked to cross-cultural management. Furthermore, this knowledge, or cultural competence, can help reduce costs linked to negotiation and the quality of productivity through an improvement of the management of human resources.

If one is unable to communicate his message, then organizational effectiveness is lacking, and this is critical, for it is estimated that "a typical manager spends as much as 80 percent of his day in communication activities" (Francesco and Gold, 1998, p. 67).

\section{Frameworks for Examining Cultures}

Understanding a culture's basic assumptions is important for understanding the culture itself. Researchers have developed frameworks to classify the cultures of the world. These frameworks are averages or norms of the value systems that compose a culture rather than exact descriptions. In other words, they represent approximate expected behavior in a culture. Obviously, not everyone in a particular culture behaves in the same way. In fact, there is often greater variation within single cultures than across cultures. The following represent the various frameworks that purport to explain cultural differences. 


\section{Kluckhohn and Strodtbeck Dimensions}

First of all, American anthropologists Kluckhohn and Strodtbeck (1961) developed a framework of six dimensions to describe the values orientation of a culture. The values orientation represent how different societies cope with various issues or problems. In the Kluckhohn and Strodtbeck framework, a culture may favor one or more of the variations or approaches associated with a particular values orientation. These orientations are: relation to nature, time orientation, basic human nature, activity orientation, relationship among people, and space orientation.

\section{Hofstede's Dimensions of Cultural Values}

A more recent study of culture focuses specifically on work-related values. In a large-scale research program of 40 countries, Geert Hofstede (1980), a Dutch researcher, collected data from IBM employees on work-related values and attitudes. In analyzing the data from more than 116,000 employees, Hofstede extracted four dimensions of values to explain the differences among cultures: individualism-collectivism, power distance, uncertainty avoidance, and masculinity/femininity. Using the average scores for each country, Hofstede developed national profiles that explain differences in work behaviors.

\section{The Chinese Value Survey}

Because Hofstede's study presents a Western view of values some researchers thought that his European values influenced his findings and theory. To prevent Western values from influencing another study, Chinese social scientists developed the Chinese Value Survey (CVS) in Chinese (Chinese Culture Connection 1987), then translated it into other languages and administered it to students in 23 different countries on five continents. Twenty of the countries were also in Hofstede's study.Four dimensions of culture emerged from the study, three similar to Hofstede's dimensions of power distance, individualismcollectivism, and masculinity/femininity. The fourth dimension, however, represents Chinese values related to Confucianism. Originally called Confucian work dynamism, it was eventually labeled longterm/short-term orientation by Hofstede.

\section{Trompenaars' Seven Dimensions of Culture}

Fons Trompenaars (1993), a Dutch economist and consultant, also developed a framework to examine cultural differences. Using Kluckhohn and Strodtbeck's theory (1961) described previously, HamptonTurner's dilemma theory (1983), and Parsons' pattern variables (1951), Trompenaars analyzed the questionnaire responses of approximately 15,000 employees representing 47 national cultures.

Trompenaars describes national cultural differences using seven dimensions. Five dimensions are about how people relate to others, including universalism versus particularism, individualism versus collectivism, neutral versus affective, specific versus diffuse, and achievement versus ascription. The sixth dimension is time orientation: past, present, or future and sequential or synchronous. The final dimension is relationship to nature: internal- or external-oriented. Just as with the Kluckhohn and Strodtbeck work, Trompenaars' dimensions represent how societies develop approaches to handling problems and difficult situations.

\section{High and Low Context Societies}

Edward T. Hall (1976), an American anthropologist, uses the concept of context to explain differences in communication styles among cultures. "Context is the information that surrounds an event; it is inextricably bound up with the meaning of that event" (Hall and Hall 1995, p. 64). Cultures can be categorized on a scale from high-to low-context. "A high-context (HC) communication or message is one in which most of the information is either in the physical context or internalized in the person, while very little is in the coded, explicit, transmitted part of the message. A low-context (LC) communication is just the opposite; i.e., the mass of the information is vested in the explicit code" (Hall 1976, p. 79). 


\section{Cultural Metaphors}

A different approach to understanding culture is the use of metaphors. Martin Gannon and his associates (1994) identify an important phenomenon or activity of a culture as a metaphor to describe it. Gannon discusses the history and culture of 17 countries and how the metaphor leads to greater understanding of cultures. In explaining each metaphor, typical behaviors in the culture are related to the metaphor.

For example, the metaphor for the United States is American football. Americans belong to several groups or teams as part of their work and social life. Membership in these groups is usually temporary, and even though contributing to the team is an important value, rewards go to individuals. Language Styles

What language style we use can influence the relationship in the process. Gudykunst and Ting-Toomey (1988) identify four different verbal communication styles: (1) direct versus indirect, (2) elaborate versus succinct, (3) personal versus contextual, and (4) instrumental versus affective. "Verbal interaction styles reflect and embody the affective, moral, and aesthetic patterns of a culture" (Gudykunst and Ting-Toomey 1988, p. 100). The words used and the way they are put together tell much about a particular culture. Gudykunst and Ting-Toomey associate the four verbal styles with cultural characteristics by referring to Hofstede's (1980) dimensions of cultural values and Hall's (1976) high- and low-context culture descriptions.

Each of the preceding cultural frameworks attempts to explain cultural differences. Some are built on and elaborate the work of others, resulting in some overlap. None of the frameworks is absolutely correct or better than the others, yet each contributes to our understanding of why people from different cultures behave differently.

It can be argued, however, that culture is the most useful variable in discussing differences in how people behave, and that communication is central to culture and the management of organizational behavior. Language is intricately linked to culture, and communication expressions challenges cultural values. In essence, organizations are communication systems. Without effective communication, organizations experience difficulty and even failure. As Fiedler, et. al. (1996) pointed out, the key contribution of IT is to support the firm, "... and this can be achieved if the capabilities and characteristics of the IT structure matches the requirements and the nature [culture] of the organization."

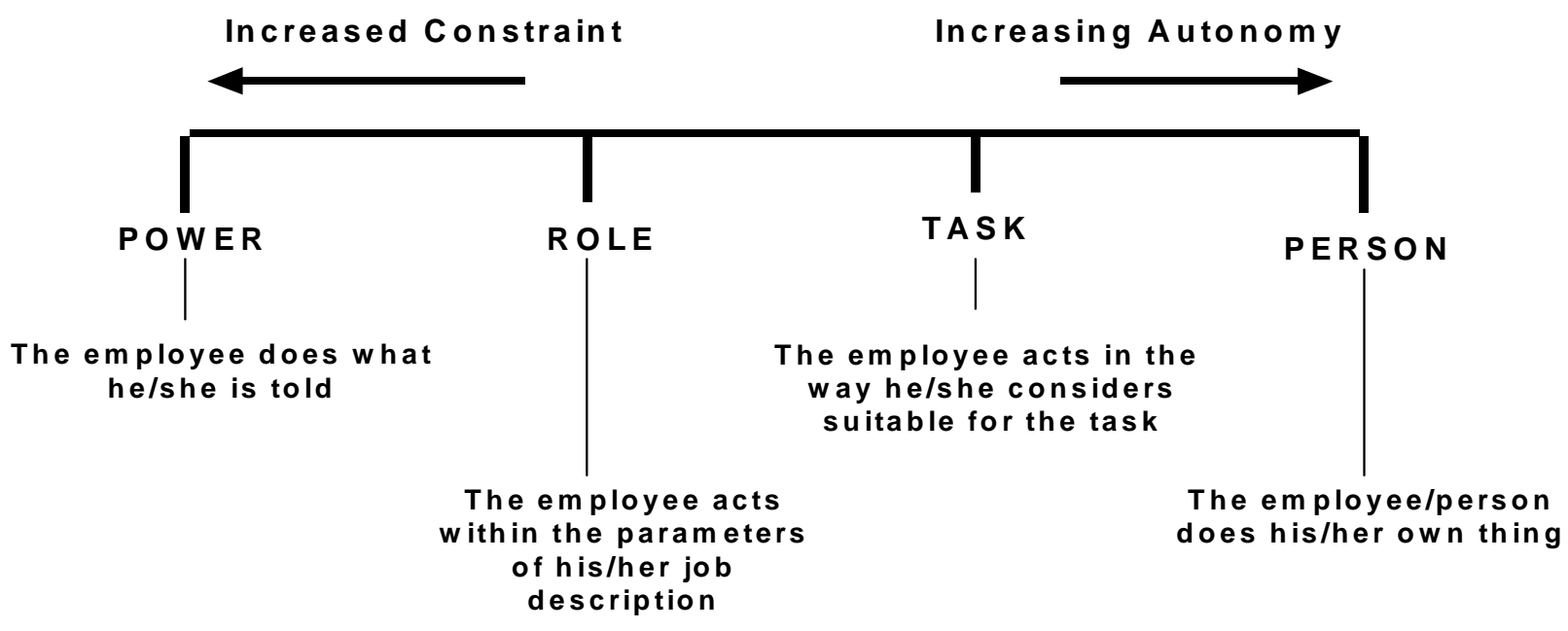

Figure 1: Orientation Continuum 


\section{Research Framework}

For the purposes of this paper, I relied upon a conceptual framework outlined by Harrison (1975) to discuss organizational culture. I used a framework by Harrison (1975) as it is directed to employees on the job, and included four orientations: Power, Role, Task and Person, or Self.

His framework allows a research to classify the four orientations into four cultural, or work values. It has been used to predict success in joint venture organizations in information technology (Cartwright and Cooper, 1989), and compare different cultures from a strategic standpoint (Merchant, 1997). Schematically, the model is shown in Figure 1.

Surveys were administered to employees in over 16 nations since 1994. Demographic data included martial status, gender, length of employment, public or private sector, educational level, organizational position, etc. Twelve cultural variables were measures. These included such items s (1) type of boss desired, (2) how decisions should be made in an organization, and (3) how conflict should be resolved, etc.

This model proposed attempts to represent the four cultural orientations of Harrison and display them as two factors: (1) the work cultures of nationalities either desiring a formal or informal organization culture and (2) their orientation toward either people or process. Schematically, the model is depicted below in Table 1.

The horizontal axis represents the cultural orientation of the employee in a nation, either reflecting his cultural bias toward people or a process. The vertical axis represents the two forms of organization culture - either formal or informal that an employee would feel comfortable working in.

\begin{tabular}{|c|c|c|c|}
\hline \multicolumn{2}{|c|}{\begin{tabular}{c}
2 \\
\multicolumn{2}{|c|}{ MULTURE-ORIENTATION }
\end{tabular}} & PROCESS \\
\cline { 3 - 4 } \multicolumn{2}{|c|}{} & PEOPLE & \\
C & F & & ROLE \\
U & O & LEADER/BOSS & (CELL 2) \\
L & R & (CELL 1) & \\
T & M & & \\
U & A & & \\
E & L & & TASK/JOB \\
& & & (CELL 4) \\
\cline { 2 - 4 } & I & & \\
& N & INDIVIDUAL & \\
& F & (CELL 3) & \\
& O & & \\
& R & & \\
& M & & \\
& L & & \\
& & & \\
\end{tabular}

Table 1: General Culture-Orientation Matrix 
Horizontal and Formal (cell 1) represents an employee who is quite comfortable in following the lead and direction of his manager. In fact, this employee would prefer to have clear direction and close supervision from his boss who is in the traditional or legalistic position of supervision. The employee is basically saying "tell me what you want me to do and how - I trust you and will follow your directions as I know that you will look out for my welfare as long as I am doing a good job."

Horizontal and Formal (cell 2) represents an employee who prefers to abide by the rules, regulations and procedures that have been outlined for his job. He has allegiance to the role that he has been hired to perform and feels that as long as everyone follows the dictates of the rules then it will be a productive company. This employee is in effect, the ideal bureaucratic man. His orientation is "don't ask me to do more than what is outlined in my duties and responsibilities."

Horizontal and Informal (cell 3) represent an employee who is oriented to people - and himself - in order to grow and develop. He wants involvement and consultation over his role and work assignment so that he can become more efficient which he feels then the company will benefit from his increased knowledge and skills. The boss should be one who involves this employee. He wants consulting and involving in what needs to be done - with a special emphasis on "I want to grow and develop within the company."

Horizontal and Informal (cell 4) represent an employee who, like his brethren in cell 3, is not concerned with the trappings of authority or role delineation. His perception is that a job needs to be done and he is capable of doing so and looks to a boss to provide the necessary tools and environment so he can do his job. He is a very independent individual in an organization. His basic orientation is, " I am good, I know my job, just help me out so that I can do it better."

In essence, a Formal Organization Culture provides a basis for authority for the employees, whether it be traditional, legal, or charismatic legitimacy, and is representative of a mechanistic organization, with rules, regulations and practices that are expected, and accepted. The employees are extremely comfortable working in an environment such as that. On the other hand, an Informal Organization Culture does not represent authority-based activities; it is an organic type organization where informality is the mode of operation. Productivity for these employees comes from involving or supporting the activities of their predisposition to operate more-or-less on their own. The employees desiring this cultural-orientation appear to be representatives of knowledgeable and self-assured individual, (knowledge workers) who are quite comfortable in this environment and do not desire either direct control or detailed rules and regulations to dictate their activities.

\section{Model Application}

One way to view the application of this model is to view it as a series of decision boxes in assessing the pre-disposition of the employee due to his cultural orientation. The question posed to the respondents was: What Type of Manager Do You Want to Work For? The four choices were:

a. One who is strong, decisive, firm, fair, protective, generous and indulgent to loyal subordinates; or

b. One who is impersonal and correct; demands from the subordinate only that which is required by the formal system; or

c. c. One who is egalitarian and uses his authority to obtain the needed resources to complete the job; or

d. d. Concerned with the personal needs and values of others, using his position to provide satisfying and growth-stimulating work opportunities. 


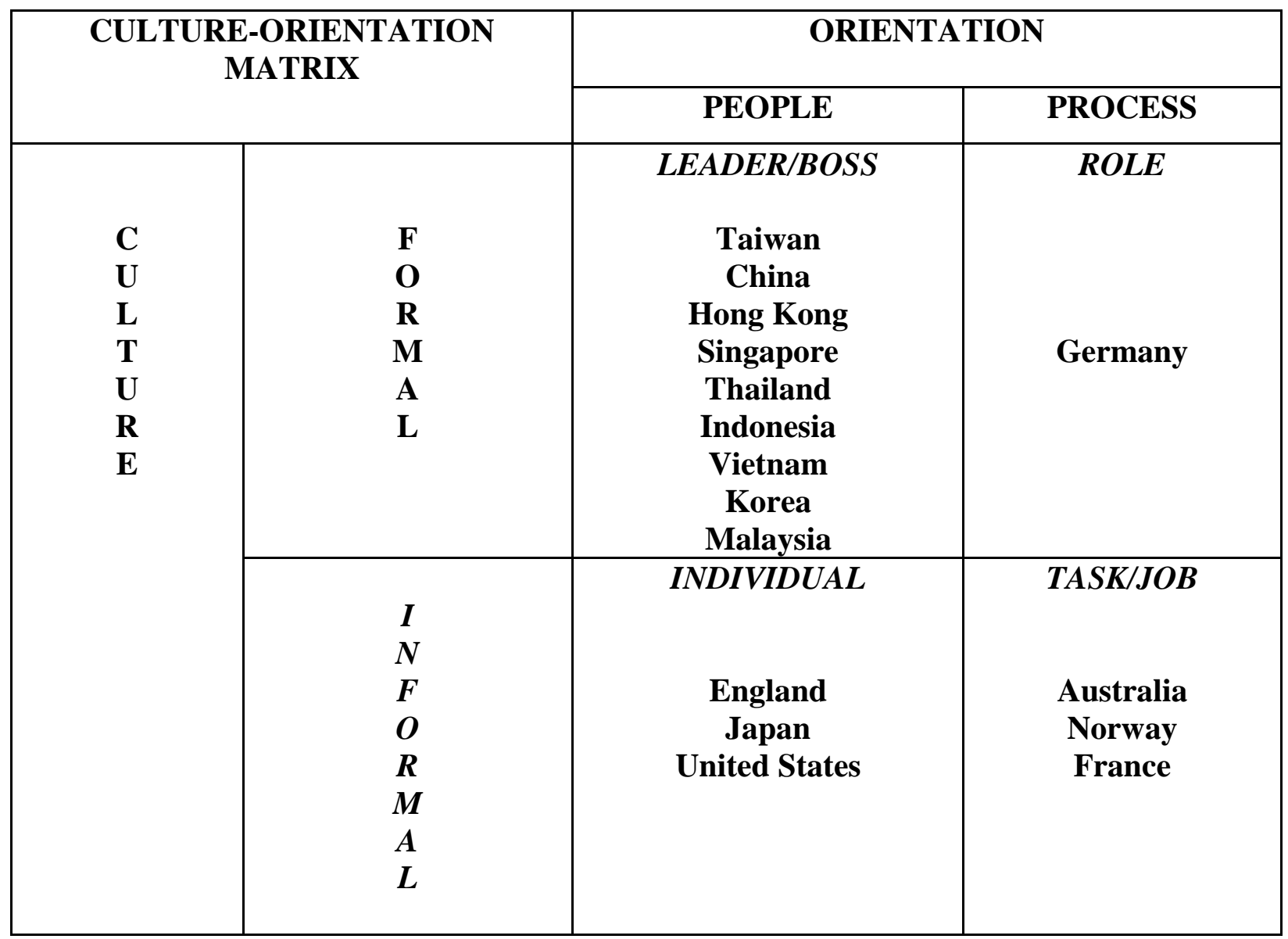

Table 2: Completed Culture-Orientation Matrix

Obviously, a is Power (Cell 1), b is Role (Cell 2), c is Self (Cell 3), and d is Task (Cell 4). Therefore, one who is oriented to relying overwhelming on his manager for direction, close supervision, and rewards in the work place would feel very comfortable in cell 1 . Nationalities who fall into this category, based on this and my previous research, include most employees from Asia, such as Thailand, China, Vietnam, and Indonesia. This finding is supported by the research of Hofstede in that all of these societies have a Large Power Distance orientation. The employee that is oriented to a set of rules and guidelines to fulfill his responsibilities would obviously feel comfortable in cell 2. In my research, Germans fall into this category. In cell 3, Informal person-oriented would be those nationalities that are predisposed to being involved in the work assignments. Nationalities here include England, United States and Japan. Finally, for cell 4, these nationalities want an informal structure, which concentrates on getting the job done and looks to the manager for support. Australia, Norway and France fall into this category. Of my research so far, the 16 nations studied can be classified according to the following scheme, shown in Table 2.

\section{Discussion}

Obviously, the application is not as simple as it seems. While it can be used in trying to understand cross-cultural differences, a few points need to be made. One, while many of the nationalities clearly fall into the cells as indicated, there are some situations whereby further refinement is needed. For example, the Germans fall into cell 2, with an orientation toward rules and regulations, and which appears to be characteristic of that society. However, a closer look at the data indicates that the males are the ones who overwhelmingly orient toward Formal-Role, while the majority of the females in the study orient toward 
Formal-Power. They are both formal in their orientation, but the female indicating they feel comfortable taking direction and look to the manager for all of her needs on the job. Again, these results tend to support the "so-called" national character of the Germans (both male and female). We must bear in mind that this not a negative finding. That is, the results do help us to distinguish between sub-cultures (based on gender) in a society. Therefore, we now know that we can approach a German male in one orientation, and at the same time, treat a German female differently. We do not see the same phenomenon in Thailand, nor in America, where both men and women reflect the same orientation.

Even with these sub-culture differences, however, we can learn from this study the variables of importance to nationalities around the world and from that prepare ourselves on the best approach to introduce change into the organization from an IT standpoint. The findings of this study are supported by the few studies undertaken in cross-culture IT application. For example, Kitchell (1995) found that culture is predictive of technology adoption. Straub et. al., (1997), in their study of the TAM across cultures, concluded that "there is a growing need to understand how cultural factors might affect multi-national organization's ability to adopt and utilize IT” (p. 9). In a separate study by Kettinger et. al., (1995) on cross-national IS Quality perceptions, they found that there exist an "Asian factor" with differing definitions of IS. A very recent study of the attitudes of three separate cultures on the adopting of IT found that culture is a crucial element that can determine acceptance or not, and that we need to consider cultural resistance to technologies (Brown et. al., (1998). This model can assist in understanding cultural differences.

\section{Conclusions}

It is a given that groups form the basic structure of organizations. And, it is also a given that work is more often than not performed by groups in an organization. Our problem today is that we do not have homogenous groups from the same nation - or culture. In our global economy, we have a mixture of Japanese, Thais, Chinese, Americans, etc., - all working within the same company, and their relationship can effect productivity. That is, actual productivity depends on how well the groups collaborate and uses its resources to accomplish the task. Cultural diversity makes group functioning more difficult. This is due to the fact that people see situations and understand them in different ways. It becomes increasingly troublesome to reach agreements. Misinterpretation, mis-perception, mis-evaluation and mis-communication are more likely to arise. The consequences are increased stress levels due to disagreements on expectations, the correctness of information and the particular decisions which must be taken, and who is to make them. Diversity increases the complexity, ambiguity and confusion in an organization. This has implications on costs. To address these issues, to insure that we maximize human performance within an organization, we need to become cultural-competent.

The first step consists of becoming conscious of one's own cultural orientation. For example, a great many Americans have a tendency to encourage "participating management." While proper in an American setting, if one would suggest it to Thai employees working for you, they would smile and say to themselves why are you asking me to decide - that is your job - just tell me what to do - period. Therefore, your action may not be the best - based on your cultural orientation.

The second is to know other cultures. That is, one must learn to recognize practices and values from other cultures and to use them in the right context. Therefore, more studies along these lines on cross-cultural differences can go a long way to bridge the gap between what we know and how to use that knowledge. This knowledge would also help to better refine and apply the model proposed within this paper.

In summary, IT has been instrumental in contributing to the effectiveness of organizations striving for competitive advantage. New developments and applications of IT have assisted many organizations, in many industries, to maximize the potential to exceed previous expectations on a global scale from a competitive standpoint. At the same time, students of IT have been exposed to, and educated in, a discussion 
of the multitude of variables that can impact on an organization's effectiveness. We have seen how IT can compete better with its rivals, suppliers, buyers, and potential entrants. We have seen how IT can impact organizational effectiveness by considering contributory studies from the fields of sociology, psychology, engineering, organizational behavior, and especially management. From this research, it became apparent, as Orlikowski and Baroudi (1991) indicated, that various research philosophies "... can offer an insightful perspective on the phenomena of interest in information systems research."

Researchers of IT have made great strides in identifying and isolating those variables which can advance the study of information technology and its contribution to the success of an organization. This practice needs to continue and all internal and external variables which could have an impact on the potential success of an organization need to be considered in order to promote the use of IT for the good of the organization and the individuals in the organization. This research can make a contribution to the study on the influence of culture and IT on an organization, and those variables that we need to understand.

As Fiedler, et. al. (1996), point out, "Further research is needed into the ultimate benefits of matching IT and organization structure." The research presented here will contribute to the advancement of IT and organizational success, in that "IT has both social and material properties, being physically and socially constructed by subjective human action, while also objectified and reified through institutionalization" ( Orlikowski and Robey 1991). In essence, the cultural orientation of the individual operating within his culture is a major key variable to consider in the implementation of Information Systems.

\section{References}

Brown, Thomas E., Ralph K. Williams, and James T. Brown, "A Comparison of Attitudes Toward Computers Among Business Professionals in China, Japan, and the United States," Journal of Computer Information Systems, volume xxxviii, number 3, Spring 1998, pp. 1-5.

Daft, Robert L. and Robert H. Lengel, "Organizational Information Requirements, Media Richness and Structural Design," Academy of Management Journal, May 1986, (32:5), pp. 554-571.

DeLone, William H. and Ephraim R. McClean, "Information Systems Success: The Quest for the Dependent Variable," Information Systems Research, March 1992, (3:1), pp. 60-90.

Cartwright, Susan and Cary L. Cooper, "Predicting Success in Joint Venture Organisations in Information Technology," Journal of General Management, vol. 15 no 1, August 1989, pp. 39-52.

Ferraro, G.P., The Cultural Dimensions of International Business, 2d ed. NJ, 1994

Fiedler, Kirk D, Varun Grover, and James T. C. Teng, "An Empirically Derived Taxonomy of Information Technology Structure and its Relationship to Organizational Structure," Journal of Management Information Systems, Summer 1996, (13:1), pp. 9-34.

Francesco, Anne Marie and Barry Allen Gold, International Organizational Behavior, Prentice Hall, NJ, 1998.

Gannon, M. J. and Associates, Understanding Global Cultures: Metaphorical Journeys Through 17 Countries, Sage Publication, CA, 1994.

Hall, E. T., Beyond Culture, Anchor Press, NY, 1976.

Harrison, Roger, "Understanding Your Organization's Character," in Harvard Business Review On Management, 1975, Harper \& Row, New York.

Hofstede, Geert., "Cultural Constraints in Management Theories", Academy of Management Executive, 1993, 7, 81-94.

Hunger, J. David and Thomas L. Wheelen, Strategic Management, 1996, Addison-Wesley, New York.

Johnston, H. R. and S. R. Carrico, "Developing Capabilities to Use Information Strategically," MIS Quarterly, March 1988, (12:1), pp. 37-88.

Kettinger, William J. Chong C. Lee, and Sunro Lee, "Global Measures of Information Service Quality: A Cross-National Study”, Decision Sciences, vol 26, no. 5, Sep/Oct 1995, pp. 569-588. 
Kitchell, Susan, "Corporate Culture, Environmental Adaptation, and Innovation Adoption: A Qualitative/Quantitative Approach", Journal of the Academy of Marketing Science, vol 23, no 3, pp. 195-205.

Kluckhohn, F. and F. L. Strodtbeck, Variations in Value Orientations, Peterson, Ill., 1961.

Mahmood, Mo A. and Siew Khim Soon, "A Comprehensive Model for Measuring the Potential Impact of Information Technology on Organizational Strategic Variables," Decision Sciences, September/October 1991, (22:4), pp. 869-897.

Markus, M. Lynne, and Daniel Robey, "Information Technology and Organizational Change: Causal Structure in Theory and Research,” Management Science, May 1988, (34:5), pp. 583-598.

Merchant, John E., "Determinants of Corporate Success: One View of Comparative Work Values of Australians and Americans," Proceedings of the Fourth International Meeting, Decision Sciences Institute, Sydney, Australia, July, 1997.

Mintzberg, Henry, J. B. Quinn, and J. Voyer, 1995, The Strategy Process, Prentice-Hall, New Jersey.

Orlikowski, Wanda J. and Jack Baroudi, "Studying Information Technology in Organizations: Research Approaches and Assumptions," Information Systems Research, March 1991, (2:1), pp. 1-28.

Orlikowski, Wanda J. and Daniel Robey, "Information Technology and the Structuring of Organizations," Information Systems Research, November 1991, (3:2), pp. 143-169.

Rockart, John F. and Michael S. Scott-Morton, "Implications of Changes in Information Technology for Corporate Strategy," Interfaces, January/February 1984, (14:1), pp. 84-95.

Straub, Detmar, Mark Keil, and Walter H. Brenner, "Testing the Technology Acceptance Model Across Cultures: A Three Country Study", Information Management, 33 (1997) 1-11.

Swanson, E. B., "Information Systems in Organization Theory: A Review," 1987, Critical Issues in Information Systems Research, John Wiley and Sons, pp. 181-204.

Trompenaars, F., Riding the Waves of Culture: Understanding Diversity in Global Business, The Economist Books, London, 1993.

\section{Biography}

John E. Merchant is a Professor of Strategic Management at California State University, Sacramento. He is also a Fellow in the World Academy of Productivity Sciences. He has taught at the United States Air Force Academy for five years and has been in his present position since 1983. He teaches undergraduate and graduate courses in Strategy, Business Policy, Research Methodology, International Business and Multinational Marketing. His current research centers on the work and cultural values of employees around the world. He has made presentations on this subject since 1994 in such diverse locations as San Francisco, Baltimore, Sweden, Istanbul, Athens, Paris, Madrid, Singapore, Taiwan, Seoul, Montreal, etc. 